\title{
A MODERNIDADE PEDAGÓGICA NO DISCURSO JURÍDICO: A NORMALIZAÇÃO DAS POPULAÇÕES INFANTIS'
}

\author{
Cynthia Pereira de Sousa *
}

\begin{abstract}
RESUMO
Este texto tem por objetivo central a sistematização e a análise das formações discursivas sobre a reforma educacional que circularam no Brasil e em Portugal, de uma perspectiva histórica e comparada. Para tanto, examinou-se os significados atribuídos à modernidade e, por extensão, à modernidade pedagógica, pela via de uma sociologia da modernidade e dos discursos produzidos no campo do Direito em fontes documentais, tais como livros, teses, códigos, compêndios, periódicos etc. No contato com essas fontes do campo jurídico, buscaram-se temas constitutivos da problemática educacional da modernidade, ou seja, aqueles ligados à moralidade, à subjetividade e ao seu controle, à observação e aos cuidados dispensados ao corpo e à alma infantis. Em suma, aqueles aspectos que se ligam à estruturação de um novo modo de governo da sociedade e das populações infantis.
\end{abstract}

Palavras-chave: Modernidade pedagógica. Discurso jurídico. Tecnologias de governo das populações infantis.

\section{ABSTRACT \\ PEDAGOGICAL MODERNITY AND THE LAW DISCOURSE; THE NORMALISATION OF CHILDREN'S POPULATIONS}

This text has as its main objective the systematization and analysis of discursive formations on the educational reform, which circulated in Brazil and in Portugal, from a historical and comparative perspective. For this purpose, we examine the meanings assigned to modernity and, by extension, to pedagogical modernity, by means of a sociology of modernity and the speeches made in the field of Law, in documentary sources such as books, thesis, codes, manuals, journals, etc. In contact with these field sources, we have sought legal topics constituting the educational problem of modernity, such as, those related to morality, subjectivity and its control, observation and care given to children's body and soul, in short, to those aspects linked to the structuring of a new kind of government for the children and the whole society.

Keywords: Pedagogical modernity. Legal discourse. Technologies of government of children's populations.

\footnotetext{
${ }^{1}$ Este texto é parte integrante do Relatório Final de pesquisa encaminhado ao CNPq, em 2009. Para os efeitos desta publicação, foram feitas algumas alterações.

* Professora Livre-Docente aposentada da Faculdade de Educação da Universidade de São Paulo (USP). Professora do Programa de Pós-Graduação em Educação da Faculdade de Educação (USP). Endereço para contato: Av. Nove de Julho, 5185 - ap. 111, São Paulo, SP. CEP 01407-200. cypsousa@gmail.com
} 
Nesta investigação sobre a modernidade pedagógica no discurso jurídico, consideramos Portugal e Brasil como uma "comunidade imaginada" (ANDERSON, 1983) ${ }^{2}$, a comunidade imaginada lusófona por pertencerem à mesma comunidade linguística, por possuírem relações históricas e culturais de longa duração, por partilharem identidades culturais, seja "por adesão, seja por rejeição". A perspectiva que aqui se coloca não é a de uma comparação que obedeça a fronteiras nacionais, geográficas, mas, ao contrário, avança e ultrapassa tais limites para pensar em um espaço de relação entre esses dois países pertencentes a dois diferentes continentes. Como assinala António Nóvoa "[...] todas as comunidades são imaginadas e distinguem-se, não por uma eventual falsidade/ autenticidade, mas justamente pelos modos como se imaginam. Eis o que conduz o comparatismo a virar-se para novas realidades, que não cabem nas geografias nacionais" (2000, p. 127).

Ao nos dedicarmos ao exame de práticas discursivas provenientes da área do Direito e o seu cruzamento com as proposições em torno da constituição de uma escola e de uma educação modernas, pensamos ser possível elaborar e constituir como resultado da pesquisa os "objetos de investigação de maior complexidade", apontados por Jürgen Schriewer (2001, p. 26) e que, em nosso corpus documental, são as matérias produzidas no campo jurídico que podem oferecer olhares alternativos sobre a modernidade pedagógica nos dois países.

Fomos buscar em um tempo histórico mais recuado (1820-1920) a proveniência ${ }^{3}$ da escola moderna, desse modelo escolar ao qual estamos tão acostumados. Isso significa, na verdade, uma tentativa de redescobrir a história da escola, nos

\footnotetext{
Para Benedict Anderson, uma "comunidade imaginada" é bem diferente de uma comunidade real, porque na "comunidade imaginada" não há interações cotidianas entre os indivíduos, que não conhecem todos os membros do grupo maior, seja da cidade, do estado, da nação. Entretanto, os membros de qualquer sociedade sentem-se unidos por uma série de referências comuns (valores, experiências, símbolos etc.), mesmo que não tenham contato uns com os outros. É o que acontece, por exemplo, em eventos de grande porte, quando sentimentos de afinidade, de nacionalismo, de comunhão de interesses são despertados nos indivíduos de toda uma nação.

3 Proveniencia é o termo empregado por Foucault, quando explica o método genealógico criado por Nietzsche. É a tentativa de "descrever uma gênese no tempo", mas não sua "origem", "porque a história ensina a rir das solenidades de origem", mas restituindo os acontecimentos na sua singularidade (FOUCAULT, 1992, p. 18 e 20-21).
}

dois espaços em que se fala a língua portuguesa, e no espaço de tempo chamado de modernidade. Nessa redescoberta é preciso assinalar que, não obstante muitos ainda pensarem o contrário, a escola não é universal e nem eterna, não existiu sempre e em todo lugar e, portanto, não pode ser naturalizada. A instituição escolar mudou bastante, desde os tempos greco-romanos, passando a cumprir funções muito diferentes nessa nova configuração social em que veio a emergir. Como espaço de passagem obrigatória para crianças e adolescentes, "a escola primária é uma instituição recente". Todavia, como instituição escolar, toda a maquinaria do governo da infância começou a entrar em atividade desde o século XVI (VARELA; ALVAREZ-URIA, 1992, p. 68). Tais mudanças caracterizam bem os diferentes cenários do advento e consolidação da escola moderna, em clara oposição à chamada escola tradicional: o período de tempo chamado de modernidade e a emergência do Estado-nação.

Palavra ambígua, conceito "escorregadio", o que é que entendemos por modernidade? Para Anthony Giddens, "modernidade refere-se a estilo, costume de vida ou organização social que emergiram na Europa a partir do século XVII e que, ulteriormente, se tornaram mais ou menos mundiais em sua influência"4, cobrindo, portanto, os últimos quatro séculos de história (1991, p. 11). Tanto quanto a história do ser humano é marcada por descontinuidades, assim também a modernidade, para a qual ele atribui descontinuidades especificas, que são mudanças em ritmo acelerado, amplitude do espaço geográfico apanhado pelas mudanças, peculiaridade das instituições modernas, tais como a ideia de Estado-nação (Idem, p. 15-16).

Apoiado em Giddens, o sociólogo alemão Peter Wagner ${ }^{5}$ assinala que, a despeito de haver quase uma unanimidade acerca das grandes transformações sociais que caracterizam o período, as análises dos estudiosos apontam para "direções diversas e,

\footnotetext{
${ }^{4}$ Para Giddens, que não aceita denominar nossa época atual de "pósmodernidade", o mais correto seria pensar que vivemos um período "em que as consequências da modernidade estão se tornando mais radicalizadas e universalizadas do que antes" (1991, p. 13).

5 “[...] el presente libro se entiende a sí mismo como una amplia reflexión sobre los conceptos giddeanos de posibilidad y limitación, e intenta definir de la mejor manera posible qué tipo de acciones y bajo qué circunstancias están posibilitadas o recortadas por las instituciones modernas.” (Wagner, 1997, p. 18, grifos nossos).
} 
às vezes, divergentes", em razão da sua incapacidade de perceber o caráter ambíguo da modernidade (1997, p. 12). Assinala que, quando se pretende fazer uma análise histórica da modernidade, é preciso estabelecer uma distinção entre os discursos sobre a modernidade e as práticas, entre o projeto da modernidade (como aspecto normativo) e as práticas das instituições das chamadas sociedades modernas. "Entre las ideas y las instituciones de la modernidad existe afinidad, pero no identidad" ( $p$. 29-30). Para Wagner, as duas ideias que presidem o discurso da modernidade são a liberdade e a autonomia. Contudo, outra interpretação "alternativa e crítica" veio opor ao quadro das liberdades por meio das instituições modernas a condição de submissão dos sujeitos por meio dessas mesmas instituições. Essa interpretação constitui os "dois retratos, universalmente conhecidos e inconciliáveis entre si" - o discurso da liberação e o discurso da submissão (p. 30). Relativos ao primeiro são os movimentos de libertação e independência: revolução científica, revoluções políticas - a Americana e a Francesa -, até a independência econômica dos Estados absolutistas. Sobre o segundo, constatou-se que o modo de viver as liberdades era muito diferente da maneira como as ideias liberais foram pensadas pelos grupos que as produziram. Da segunda metade do século XVIII até 1850 , mais ou menos, o continuísmo foi uma das características de sociedades europeias saídas de movimentos revolucionários. Ao Estado moderno, encarnação social da Razão, atribuía-se o poder de manter a ordem em toda a sociedade e de concretizar "os hábitos e as práticas sociais ilustradas". Todavia, essa forma de Estado também funcionou como "freio", como limitação das vontades, das liberdades e das práticas sociais de autonomia dos indivíduos (p. 30-34).

Ao longo do século XIX, essa forma de Estado é o Estado-nação, em cujo quadro de afirmação desenvolveram-se e consolidaram-se os sistemas nacionais de ensino iniciados pela base, ou seja, pela organização da escola elementar. Essa é a escola primária de configuração recente, segundo Varela e Alvarez-Uria (1992). Estudos que utilizam a teoria da difusão mundial da educação de massas (mass schooling ou mass education) demonstram que esse modelo escolar desenvolveu-se com relativa homogeneidade, em todo o mundo, desde finais do século XIX, quando o modelo de naçãoEstado apareceu, a despeito das variações internas, das especificidades socioeconômicas, do aparato político, das diferenças étnicas e mesmo das religiões. No bojo desse modelo de Estado-nação, a educação de massas tornou-se um componente central e, depois da Segunda Grande Guerra, a escola elementar avançou de forma significativa, intensiva e extensivamente (BOLI; RAMIREZ; MEYER, 1985, p. 145). Ao longo do século XIX ficaram evidenciadas as intenções modeladoras e disciplinadoras do Estado, que procurou normalizar a infância e a juventude e, com isso, formar o cidadão responsável, o trabalhador produtivo, o pai virtuoso, o marido fiel, o soldado patriota, o eleitor honesto ou submisso. Assiste-se à transferência do poder (simbólico) da Igreja para o Estado, doravante Estado educador, rompendo-se o monopólio eclesiástico sobre o campo educacional:

By the nineteenth century sovereignty was fully transferred from God to humanity, the individual and the State had become the central elements of society, and the pursuit of rational progress as the primary purpose of autonomous human society was winning the institutional high ground. These developments made schooling seem imperative, the best way to transform children into the new type of enhanced and capable citizen who could create this new progress-oriented society (BOLI \& RAMIREZ, 1992, p.29).

É necessário enfatizar que a escola moderna ou, como escreve Nóvoa, o modelo escolar moderno teve como seu prolongamento, sua extensão, a escola de massas, cuja origem é europeia, daí se difundindo para outras partes do mundo. Não causa surpresa, portanto, que "o discurso filosófico da modernidade [e, acrescentaríamos, o discurso pedagógico] seja, por definição, eurocêntrico" (NÓVOA, 1998, p. 92). E a modernidade foi construída com base na ideia de progresso em todas as instâncias e de reforma da escola tradicional, fazendo da escola de massas o espaço de desenvolvimento de um meticuloso trabalho de construção e consolidação de uma cultura nacional.

Nesse cenário da criação dos sistemas nacionais de ensino e o desenvolvimento da escola de massas, outra questão fundamental foi a emergência de um novo modelo disciplinar, da maquinaria de admi- 
nistração social das populações e de governo das almas infantis ${ }^{6}$. Ao lado da sobrevivência de certas práticas repressivas, a escola moderna pretendeu formar o aluno enquanto corpo, alma e mente, desenvolvendo processos de auto-observação, autorregulação, de controle introspectivo, de fortalecimento da vontade sobre os maus hábitos. Em outras palavras, a escola moderna treinou os educandos para que cada um fosse capaz de submeter o mal, o anormal, o vício, para que o bem, o normal e a virtude saíssem vencedores. Um primoroso trabalho de subjetivação, expressão foucaultiana, foi iniciado por escolas, igrejas e autoridades e, depois, continuado pela instituição escolar.

Ao tomar o campo do Direito ${ }^{7}$, no século XIX e início do século XX, e tentar enveredar pela análise de conceitos caros ao discurso da modernidade, tais como liberdade, autonomia e suas implicações sobre a construção da nacionalidade, da soberania e da cidadania, teríamos que considerar, inescapavelmente, a escola de massas, pública e obrigatória, pois foi ela o locus privilegiado para forjar novos cidadãos e dar seguimento ao processo de modernização do Estado.

Analisar a modernidade pedagógica no discurso jurídico, nos dois países da comunidade lusófona, possibilita articular uma série de questões que evidenciam os embates, os interesses em jogo, as teses em disputa, as teses vencedoras, mais que tudo os sinais da anterioridade de certas ideias modernas aí presentes, antes mesmo de se ter historicamente constituído o campo das ciências da Educação como um domínio autônomo no âmbito das Ciências Sociais.

\section{Literatura jurídica no século XIX}

Em Portugal, e para mencionar apenas dois ramos do Direito, a produção em Direito Civil foi

\footnotetext{
Embora esse modelo também seja aplicável à escola secundária ou aos liceus, nós nos ativemos à escola primária.

Cf. Biblioteca Digital Ardies. Essa biblioteca disponibiliza a edição eletrônica dos principais títulos da literatura jurídica portuguesa do século XIX até a primeira metade do sáculo XX. As obras selecionadas teivera como critério o local de sua produção - o meio acadêmico. Todavia, foram integrados à coleção "outros materiais jurídicos, de natureza diferente, complementares das anteriores (códigos, repertórios, coleções de legislação ou legislação 'avulsa', coleções de decisões dos tribunais, debates parlamentares de matérias jurídicas, algumas obras de divulgação jurídica)".
}

maior, numericamente falando, que a de Direito Penal, e, em ambos os casos, o maior volume de obras foi publicado a partir de $1850^{8}$. Boa parte dessa produção, ao longo de todo o século XIX e, às vezes, com vários títulos de um mesmo autor, consiste de comentários, apreciações, elementos, subsídios, aspectos, observações, estudos, lições, tratados, teorias, manuais, história, bibliografia etc., relativos aos dois Códigos. Um número menor de textos trata de assuntos mais pontuais: classificação dos crimes e penas correspondentes (1803); sobre delitos e penas (1816); sobre a necessidade e meios de melhorar as prisões em Portugal (1834); se é justo adotar a deportação para pena (1859); a reforma das cadeias em Portugal (1860); os encarcerados (1889); discurso sobre a pena de morte e reflexões sobre alguns crimes $(\mathrm{s} / \mathrm{d})$. Em Direito Civil: testamentos e sucessões (1844); a sucessão dos filhos ilegítimos (1861); sucessão dos filhos naturais (1871); ignorância ou erro de direito (1871); legitimação de filhos espúrios (1860); casamento civil (1881); capacidade civil (1905); a responsabilidade civil baseada no conceito de culpa (1906). Nessa listagem não aparecem temas específicos sobre outras situações da infância - a desvalida, a órfã, a abandonada, a "perigosa".

$\mathrm{O}$ exame da literatura jurídica produzida no Império brasileiro, segundo levantamento e notas críticas feitos por Pedro Dutra (2004, p. 141-170), pode nos dar uma ideia do que se publicava. Civil, Penal e Processual são os ramos do Direito em que esses temas aparecem, sob a forma de compêndios, manuais, livros, teses: guias dos juízes de órfãos, tutores e curadores e de todos os escrivães (1833); primeiras linhas sobre processo orfanológico (1851 e 1865); sucessão dos filhos naturais e sua filiação (1857); processo orfanológico (1863-1868); direitos de família (1869); instituições orfanológicas (1874); testamentos e sucessões (1881); filhos naturais reconhecidos e direitos hereditários (1884); menores e loucos em direito criminal (1886).

Dutra não fez observações sobre nenhum desses textos, nem mesmo sobre o famoso livro de Tobias

\footnotetext{
86 6"El Derecho es la institución par excellence creadora de individuos autónomos que son - y a quienes se puede hacer - a los ojos de todos los Otros relevantes, responsables de sus actos" (WAGNER, op. cit., p. 41).
} 
Barreto intitulado Menores e Loucos, publicado em 1886, pois concentrou-se em obras consideradas clássicas pelos agentes do campo no período pesquisado. Seu levantamento também se apoiou em catálogos de livrarias, como a famosa Garnier que, em 1862, trazia uma relação de "123 rubricas" relacionadas com assuntos jurídicos.

Uma infinidade de gêneros é oferecida: assessor forense, a arte de requerer, o advogado comercial, análise, apontamentos, anuário, apêndice, classificação, coleção, códigos, compêndios, considerações, curso, dicionários, dissertações, elementos, ensaios, exemplários, esboço, formulários, guias, história, índices, lições, manuais, métodos, noções, observações, praxe, preleções, princípios, prática, regimentos, regulamentos, regras, roteiros e tratados (idem, p. 104). Nos finais do século XIX e inícios do século XX, os temas da infância, criança, menor, educação passarão a ser mais frequentes em alguns periódicos jurídicos, dissertações e teses defendidas em faculdades de Direito e, ainda, sob a forma de livros publicados. Há, todavia, outro aspecto a ser considerado na literatura jurídica: temos que nos defrontar com textos cuja linguagem ${ }^{9}$ é cheia de alusões e referências a outros autores e escolas, no meio dos quais às vezes se dilui a opinião do próprio autor. Além disso, a leitura é muito técnica para aqueles que não pertencem ao campo. Interessante estudo sobre a família no discurso jurídico do século XIX revela alguns problemas dessa natureza. Não obstante ser um pouco longo, vale a pena transcrever os comentários em sua íntegra:

A análise das teses e dos textos jurídicos enfrentou alguns obstáculos. O primeiro é a relativa impermeabilidade da teoria jurídica aos outros ramos do saber social. As teses de medicina e de higiene têm o tom de um discurso moralista e a forma de um arrazoado de definições, mescladas de argumentos científicos, cujo caráter ideológico é transparente. Nesse sentido elas podem ser lidas por qualquer leigo. Já as teses e dissertações de direito [e os textos jurídicos] são de

\footnotetext{
9 Pierre Bourdieu assinalou que "como toda a linguagem douta, a linguagem jurídica consiste num uso particular da linguagem vulgar [...]". Em uma nota afirma: "Deste conjunto de exigências constitutivas da visão do mundo jurídico deriva, segundo J.-L. Austin, o fato de os juristas não darem às expressões correntes o seu sentido corrente e de, além de inventarem termos técnicos ou sentidos técnicos para termos correntes, manterem uma relação especial com a linguagem que os leva a procederem a extensões e restrições de sentido insólitas" (1989, p. 226 e 230).
}

outra natureza. Embora a ciência jurídica faça parte das chamadas ciências sociais, ela constitui um universo teórico bastante impermeável aos outros ramos do saber social e, até certo ponto, inacessível aos não iniciados. Nesses trabalhos há sempre uma mescla de termos de linguagem técnica, com afirmações de princípio em frases lapidares e alusões abruptas a autores ou correntes filosóficas, aparentemente deslocadas, em uma retórica codificada internamente à ciência jurídica. Vale dizer que os textos não são inteligíveis em si, a não ser reinseridos no quadro do debate político e filosófico das correntes jurídicas da época. Por tudo isso, escasseiam no Brasil e em geral, os trabalhos que ultrapassem essa retórica e ponham a evolução do saber jurídico em contato com os outros elementos da vida social (ALMEIDA, 1999, p. 19-20).

\section{Os menores na legislação}

Como é que os profissionais do direito e as autoridades constituídas perceberam, por meio dos seus discursos, propostas e ações, as infâncias, ou seja, as diferentes condições infantis em uma sociedade dita moderna e em transformação urbano-industrial? Em duas das especialidades do Direito, o Civil e o Criminal, é possível encontrar algumas referências acerca da condição da criança: como filha de família e, nesse caso, com direito a partilha de bens, ou, no polo oposto, em situação de abandono e marginalidade. Como um primeiro exemplo, mas nos inícios do século XX, a consulta a um dos volumes de índices da Revista dos Tribunais, publicada em São Paulo e relativo aos números 1 a 87 (1912-1998), apresenta quatro páginas de referências ao assunto menor. Entre 1912 e 1920 foi possível verificar os desdobramentos: bens de menor; emancipação; filiação legítima e ilegítima; filiação natural; abertura de negócio em seu benefício; adoção; responsabilidade civil dos pais; benefício da restituição; castigo; castigos imoderados; corrupção de menores; moralmente abandonado; idade de discernimento, menoridade, etc. Há várias referências, também, à legislação de proteção ao menor, mas que só seria decretada na década de 1920 e, portanto, para além de nossa periodização. Todas as referências ao menor são adjetivadas: abandonado, pervertido, ausente, delinquente, emancipado, impúbere, púbere. 
Tanto em Portugal quanto no Brasil, menor é um conceito que passou a ser usado no campo jurídico mais amplamente nos inícios do século XX, muito embora suas origens estejam fincadas no XIX, como bem o demonstram os textos das codificações que consideram tanto as crianças "herdeiras" e "legítimas", quanto órfãs, desvalidas, delinquentes, marginalizadas ${ }^{10}$. Do período colonial aos tempos pós-Independência, o termo era relacionado com a palavra idade. Para os juristas dos meados do século XIX, os termos menor e menoridade referiam-se também à idade, mas passaram a constituir-se como "um dos critérios que definiam a responsabilidade penal do indivíduo pelos seus atos" (LONDOÑO, 1991, p. 130). No Código Criminal do Império, de 1830 , foram estabelecidas três faixas etárias, até os 21 anos (quando se atingia a maioridade), traduzindo a condição legal dos indivíduos por conta de atos considerados criminosos e suas respectivas penalidades. Assim, os menores de 14 anos não poderiam ser responsabilizados criminalmente ${ }^{11}$, a menos que tivessem "obrado com discernimento", e aí seriam "recolhidos a casas de correção" (art. $\left.10^{\circ}\right)$. A decisão sobre se o menor tinha ou não discernimento na hora do delito ficava a critério do juiz, que podia condenar crianças, por exemplo, com 7, 8 ou 9 anos. Pouco mais de 20 anos depois, o Código Penal Português (1852) repetia as mesmas determinações, no seu artigo $23^{\circ}$, quanto à imputabilidade penal:

Não podem ser criminosos:

$\mathbf{1}^{\mathbf{0}}$ Os loucos de qualquer espécie, exceto nos intervalos lúcidos;

$\mathbf{2}^{\mathbf{O}}$ Os menores de sete anos;

\footnotetext{
${ }_{10}$ No caso brasileiro, houve discordância quanto a esse ponto entre a antropóloga Mariza Correa e o historiador Boris Fausto. Para ela, a passagem do conceito de "criança" para "menor" teria ocorrido nos anos 20 do século XX. Para Boris Fausto, o conceito já tinha sido formado anteriormente e, nos anos 1920, ele se consolidou na forma de dispositivos legais para a infância. Cf., Londoño, op. cit., p. 145, nota 37. Concordamos com Fausto e Londoño, pois, em todas as revistas e jornais jurídicos examinados, desde os inícios do século XIX, o termo utilizado para se referir às crianças, de qualquer condição, é menor.

11 "Art. $10{ }^{\circ}$ Também não julgarão criminosos: $1 .^{\circ}$ Os menores de 14 anos; $2 .^{\circ}$ Os loucos de todo gênero, salvo se tiverem lúcidos intervalos, e neles cometerem o crime. (...) Art. $13 .^{\circ}$ Se se provarem que os menores de 14 anos, que tiverem cometido crimes, obraram com discernimento, deverão ser recolhidos a casas de correção, pelo tempo que ao Juiz parecer, com tanto que o recolhimento não exceda a de dezessete anos".
}

$3^{\mathbf{0}}$ Os maiores de sete e menores de quatorze, quando praticam o ato sem o necessário discernimento;

$4^{0}$ Os ébrios, se a embriaguez é completa, casual, e não posterior ao projeto de cometer o crime;

$\mathbf{5}^{\circ}$ Os que praticam o ato em virtude de obediência devida, nos termos em que a lei determinar.

Entretanto, é preciso que assinalemos outra perspectiva para os tipos de penalização destinada aos menores. As preocupações com a situação da população infantil e jovem ainda eram pouco significativas, após a entrada do Brasil na fase pós-Independência e até, pelo menos, a metade do século XIX. Nesse período, o que mais se evidenciava em relação aos menores, na perspectiva da legislação, eram questões acerca dos órfãos e enjeitados e do seu recolhimento pela roda de expostos, instituição em pleno funcionamento desde o século XVIII. Entretanto, quando se lança um olhar para sua situação antes e depois do Código Criminal de 1830, percebe-se que, em um sentido pelo menos, as crianças e os jovens escaparam da morte e das galés graças à nova legislação, que determinou a prisão com trabalho (RIZZINI, 2000, p. 9). O ponto que chama também nossa atenção é o fato desse Código ter mencionado "casas de correção" nas quais os menores deveriam ser recolhidos. Em que pese a necessidade de sua criação e organização (o que foi ocorrendo a longo do século XIX, mas com mais vigor na sua segunda metade, e, ao menos, nos centros urbanos mais populosos do Império), trata-se de um claro exemplo de instituição para a gestão fisica e moral dos indivíduos, compondo o tripé - vigilância, controle e correção - que, na perspectiva de Foucault, deve ser entendido como "aparelho de normalização dos indivíduos" ${ }^{2}$. É uma evidência da anterioridade da modernidade pedagógica no campo jurídico, ou seja, a indicação, na letra da lei, de estabelecimentos especiais para "corrigir" os menores, considerados fora da norma. Essa indicação do Código "chega a ser

\footnotetext{
12 "Pode-se, portanto, opor a reclusão do século XVIII, que exclui os indivíduos do círculo social, à reclusão que aparece no século XIX, que tem por função ligar os indivíduos aos aparelhos de produção, formação, reformação ou correção de produtores. Trata-se, portanto, de uma inclusão por exclusão. Eis porque oporei a reclusão ao sequestro; a reclusão do século XVIII, que tem por função essencial a exclusão dos marginais ou o reforço da marginalidade, e o sequestro do século XIX, que tem por finalidade a inclusão e a normalização" (FOUCAULT, 2003, p. 114).
} 
surpreendente porque ainda não estava em voga a discussão sobre a importância de a educação estar em prevalência sobre a punição, o que só viria a ocorrer no final do século XIX" (RIZZINI, op. cit., p. 10, grifos nossos).

Para Tobias Barreto, no entanto, esse código de 1830 , artigo $10^{\circ}$, mereceu severas críticas em sua obra Menores e Loucos, publicada décadas depois, em 1886. De acordo com o jurista, não haviam sido feitas as devidas distinções em relação aos sujeitos considerados irresponsáveis do ponto de vista penal. Especial atenção deveria ser dada aos loucos, às mulheres e aos menores. Com relação a esses últimos, Barreto fixou as idades de responsabilidade criminal em função do nível de instrução da criança, o que, para ele, seria o elemento capaz de desenvolver a consciência do dever, a responsabilidade diante dos atos praticados. Dada a má situação da educação e das escolas no país, ampliou a menoridade até os 18 anos para, talvez, garantir um tempo maior de aprendizagens. Toda a questão poderia ser resumida no complexo e vago critério do discernimento, também presente no Código Penal Português $(1852)^{13}$. Em seu artigo $73^{\circ}$ assinalava que:

O menor de quatorze anos, que cometer algum crime, praticando o fato sem discernimento, será entregue, segundo as circunstâncias, ou a seus pais, parentes, e tutores, ou será recluso em uma casa de educação pelo tempo que for determinado na sentença (grifos nossos).

Comparadas as determinações dos dois códigos brasileiros, o de $1830 \mathrm{com}$ as do novo Código Penal, que veio a lume em 1890 , a relação entre punição/disciplina/educação fica claramente estabelecida. Em outras palavras, como medida punitiva determinou-se o recolhimento em instituições disciplinares "industriais", mantendo-se a questão do discernimento como peça importante e conclusiva no julgamento do menor.

Art. 30. Os maiores de 9 anos e menores de 14, que

\footnotetext{
13 “Artigo $73^{\circ}$. $\uparrow 1^{\circ}$ - O menor de quatorze anos, que cometer algum crime a que corresponda alguma das penas maiores, praticando o fato com discernimento, será condenado a prisão com trabalho ou sem ele, por tempo que não exceda a dez anos. Se a pena do crime for correcional, a pena que lhe for imposta não será maior do que a metade do que deveria impor-se no caso em que o criminoso excedesse a idade dos quatorze anos" (grifos nossos).
}

tiverem obrado com discernimento, serão recolhidos a estabelecimentos disciplinares industriais, pelo tempo que ao juiz parecer, contanto que o recolhimento não exceda á idade de 17 anos (Código Penal, 1890).

Talvez outro estudo, que investigue os percursos de formação de membros que integraram comissões de elaboração de projetos de lei sobre proteção e educação da infância e os parlamentares que votaram pela sua aprovação, entre finais do século XIX e inícios do século XX, possa nos dar uma medida mais exata dos esforços e da participação de juristas, médicos, políticos, pedagogos, filantropos em propor medidas e denunciar o descaso às populações infantis em situação de vulnerabilidade social. "Eram vozes que apontavam a necessidade de atingir, sobretudo, a infância que se encontrava moralmente abandonada, até então sujeita à má influência de famílias viciosas ou entregue a instituições de caridade" (RIZZINI, 2008, p. 27).

\section{As populações infantis e os discursos normalizadores: "futuro da Nação" ou "ameaça à sociedade"?}

O sentido do termo população, segundo Foucault, deve ser tomado como mais uma das táticas e técnicas da governamentalidade. O sentido explicita-se ao constatar-se o que o Estado passa a considerar como alvo principal de seu governo. Em lugar do modelo da família emerge o problema da população, e a família transforma-se no seu segmento e adquire uma "dimensão instrumental" (FOUCAULT, 1992, p. 289).

As crianças de diferentes condições passam a compor as populações infantis e, como observa Popkewitz,

a noção de 'populações' opera em geral e especificamente na construção da individualidade. A norma da população substitui a noção de indivíduos, que têm características pessoais, por aquela de grupos, que têm traços genéricos baseados em agregados e médias estatísticas. Contudo, esses retratos estatísticos transformam-se em interações sociais quando são reexaminadas como traços individuais de crianças que estão inerentemente 'em risco', ou são perigosas para a estabilidade da escola ou da sociedade [...]. (2001, p. 137). 
Como futuro da nação, elas precisavam ser salvas. Como ameaça e perigo, elas deviam ser isoladas, educadas moralmente, conformadas, modeladas, por meio de tecnologias de controle das subjetividades infantis. No cruzamento dessas diversas instâncias, surgiram propostas de intervenção nos processos educativos, diretamente nas escolas primárias e secundárias, ou em outras instituições que, embora não propriamente escolares, tinham algum alcance pedagógico: os diversos tipos de instituições de assistência às crianças desamparadas, anormais, criminosas, infratoras ou com dificuldades de enquadramento social. Em outras palavras, tratava-se de um treino moral, elaborado, defendido e proposto em diversos campos da produção intelectual, ainda antes da constituição de um campo pedagógico autônomo.

Em Portugal, como no Brasil, assistiu-se a transição da assistência caritativa, mantida pela iniciativa privada e de cunho religioso (os recolhimentos ou asilos, de forte presença até a primeira metade do século XIX), para a emergência de instituições que, em parceria com o Estado ou sob sua tutela, e embasadas em determinados dispositivos legais, vão recolher as crianças e também educá-las moralmente. A caridade cede lugar à filantropia, que se desenvolve em associação com órgãos públicos.

A fundação da Sociedade de Beneficência para Asilos da Infância Desvalida de Coimbra, em 1850, é paradigmática da parceria entre a organização política do Estado moderno e os interesses morais expressos pela organização eclesiástica. Aquele patrocinando e regulando, essa detendo as competências práticas do exercício do auxílio (RUFINO et al, 2003, p. 30).

Futuro da Nação ou ameaça à sociedade? Criança em perigo ou perigosa? Essa visão ambivalente, esses pares opostos permearam as sociedades modernas, em processo de urbanização e industrialização. No final do século XIX, no Brasil, a infầncia pobre foi identificada como um grave problema social a ser enfrentado e solucionado, por meio de instituições formadoras e transformadoras das condutas infantis. Esses modos de representação das crianças pelo discurso jurídico, como também pelo discurso médico, eram concepções correntes em outras instâncias sociais.
Em seu nome justificar-se-á a criação de um complexo aparato médico-jurídico-assistencial, cujas metas eram definidas pelas funções de prevenção, educação, recuperação e repressão. Em discurso caracterizado pela dualidade - ora em defesa da criança, ora em defesa da sociedade - estabelecemse os objetivos para as funções acima: de prevenção (vigiar a criança, evitando a sua degradação, que contribuiria para a degeneração da sociedade); de educação (educar o pobre, moldando-o ao hábito do trabalho e treinando-o para que observe as regras do 'bem viver'); de recuperação (reeducar ou reabilitar o menor, percebido como vicioso, por meio do trabalho e da instrução, retirando-o das garras da criminalidade e tornando-o útil à sociedade); de repressão (conter o menor delinquente, impedindo que cause outros danos e visando a sua reabilitação pelo trabalho) (RIZZINI, 2008, p. 26, grifos da autora).

Nessa conjunção de instâncias disciplinares - o aparato médico-jurídico-assistencial -, a medicina pública faria os diagnósticos e indicaria os tratamentos de recuperação, mas era aos agentes do campo jurídico que cabia elaborar as leis para regular tanto a proteção da infância quanto da própria sociedade, consagrando a educação, ao invés da punição, como medida de formação e transformação, de reconversão social das crianças e dos jovens.

\section{Comentários finais}

Este estudo sócio-histórico-comparado procurou compreender quais foram as transformações operadas no campo do Direito e de que modo elas projetaram a mudança educacional, em um período anterior ao advento e vulgarização das Ciências da Educação. Buscamos desvendar quais as razões dessa anterioridade da modernidade educativa e quais os fatos que poderiam explicar essa antecipação. As respostas apontaram, em primeiro lugar, para as próprias demandas do Estado-nação, do Estado-educador, em torno do projeto da chamada Educação Nova, de matriz iluminista-liberal; tais demandas foram seguidas pelos escritos de intelectuais, cientistas e homens de saber dos mais variados campos do conhecimento e, em nossa investigação, do campo jurídico.

Aqui concebida como uma expressão prática das tecnologias do governo da alma infantil, a 
moderna escola de massas iniciou seu processo de organização durante a segunda metade do século XIX. Tendo-se em conta as especificidades do Brasil e de Portugal, pode-se afirmar que tais tecnologias - como exercício de subjetivação, como treino moral - foram elaboradas, defendidas e propostas em diversos campos da produção intelectual, ainda antes da constituição de um campo pedagógico autônomo. Os conhecimentos produzidos na área do Direito, ao longo do período investigado, resultaram em um conjunto de estudos para a classificação e o controle das subjetividades infantis, expressos na legislação, em alguns peri- ódicos jurídicos e acadêmicos, em livros, teses e dissertações.

Tais estudos, portanto, configuraram propostas de intervenção nos processos educativos, desenvolvidos tanto em escolas de educação primária quanto em instituições de atendimento às populações infantis "em risco", distribuídas em várias categorias classificatórias: crianças desamparadas, anormais, criminosas, infratoras ou com dificuldades de ajuste social - a criança perigosa. Foi sobre essa criança que os hermeneutas da infância ${ }^{14}$ - pedagogos, psicólogos, médicos, juristas, - voltaram suas atenções.

\section{REFERÊNCIAS}

ALMEIDA, Angela Mendes de. Família e modernidade: o pensamento jurídico brasileiro no século XIX. São Paulo, Porto Calendário, 1999.

ANDERSON, Benedict. Imagined Communities. Reflections on the origin and spread of nationalism. London/ New York, Verso, 1983.

BIBLIOTECA DIGITAL ARDIES. Literatura jurídica portuguesa do século XIX até a primeira metade do século XX. Disponível em: <http://www.fd.unl.pt/ConteudosAreas.asp?Area=BibliotecaDigital>. Acesso em: 20 mar. 2009.

BOLI, John; RAMIREZ, Francisco; MEYER, John. Explaining the origins and the expansion of mass education. Comparative Education Review, v. 29, nº 2, may, 1985. p. 145-170.

BOLI, John; RAMIREZ, Francisco. Compulsory schooling in the Western cultural context. In: ARNOVE, Robert; ALTBACH, Philip; KELLY, Gail. (eds.) Emergent issues in education: comparative perspectives. New York, State University of New York Press, 1992, p. 25-45.

BOURDIEU, Pierre. A força do direito. Elementos para uma sociologia do campo jurídico. In: BOURDIEU, Pierre. O poder simbólico. Trad. de Fernando Tomaz. Lisboa/Difel; Rio de Janeiro/Bertrand Brasil, 1989.

BRASIL. Código Criminal do Império. Rio de Janeiro, 1830.

BRASIL. Código Penal, 1890.

DUTRA, Pedro. Literatura jurídica no Império. $2^{\text {a }}$ ed. revista e ampliada. Rio de Janeiro, Padma, 2004.

FOUCAULT, Michel. Microfísica do poder. Organização, tradução e introdução de Roberto Machado. $10^{\mathrm{a}}$ ed. Rio de Janeiro, Edições Graal, 1992.

FOUCAULT, Michel. A verdade e as formas jurídicas. Trad. de Roberto Machado e Eduardo Jardim Morais. $3^{\mathrm{a}}$. Ed. Rio de Janeiro, Nau Editora, 2003. 160p.

GIDDENS, Anthony. As consequências da modernidade. Trad. de Raul Fiker. São Paulo, Editora da UNESP, 1991.

KEY, Ellen. The century of the child. New York/London, Putnam's Sons, 1909. 336p. Disponível em: <http:// www.archive.org/details/centuryofchild00keyeuoft>. Acesso: em 14 abr. 2009.

LONDOÑO, Fernando Torres. A origem do conceito menor. In: PRIORE, Mary Del (org.) História da criança no Brasil. São Paulo, Contexto, 1991, p. 129-145.

${ }^{14}$ Tratamos da questão em pesquisa apoiada pelo CNPq. Cf. SOUSA, 2004. 
NÓVOA, António. Modèles d'analyse em Education Comparée: le champ et la carte. In: NÓVOA, António. Histoire \& Comparaison: essais sur l'éducation. Lisbonne, Educa, 1998, p. 51-84.

NÓVOA, Antonio. Tempos de escola no espaço Portugal-Brasil-Moçambique: dez digressões sobre um programa de investigação. In: NÓVOA, António; SCHRIEWER, Jürgen. A difusão mundial da escola. Lisboa, Educa, 2000, p. 121-142.

POPKEWITZ, Thomas. Lutando em defesa da alma. A política do ensino e a construção do professor. Trad. de Magda França Lopes. Porto Alegre, Artmed, 2001.

PORTUGAL. Código Penal Português, 1852.

\section{PORTUGAL. Código Civil Português, 1867}

PRADO, L. G. Gyges. Revista dos Tribunais. Índice Geral Alfabético e Remissivo. Volumes I a LXXX. São Paulo, 1935.

RIZZINI, Irene. A criança e a lei no Brasil. Revisitando a história (1822-2000). Rio de Janeiro, CESPI/USU; Brasília, UNICEF, 2000.

RIZZINI, Irene. O século perdido. Raízes históricas das políticas públicas para a infância no Brasil. $2^{\mathrm{a}}$ ed. São Paulo, Cortez, 2008.

RUFINO, César; LIMA, Ana Laura Godinho; RODRIGUES, Flávia Sílvia. Para uma história da reeducação e assistência a menores em Portugal e no Brasil, dos séculos XIX e XX: discursos e instituições. Lisboa, Educa, 2003 (Cadernos Prestige, $n^{\circ}$ 15).

SCHRIEWER, Jürgen. Formas de externalização no conhecimento educacional. Lisboa, Educa, 2001 (Cadernos Prestige, $\left.n^{\circ} 5\right)$.

SOUSA, Cynthia Pereira de. Infância, pedagogia e escolarização: a mensuração da criança transformada em aluno, em Portugal e no Brasil (1880-1960). Lisboa, Educa, 2004 (Cadernos Prestige, nº 23). 76p.

VARELA, Júlia \& ALVAREZ-URIA, Fernando. A maquinaria escolar. Teoria \& Educação, vol. 6, 1992, p. 6896.

WAGNER, Peter. Sociología de la Modernidad - libertad y disciplina. Trad. de Marciano Villanueva Salas. Barcelona, Editorial Herder, 1997. 